Research Article

\title{
Multiobjective Programming Strategy of Small- and Medium- Sized Microenterprise Credit Based on Random Factors
}

\author{
Zhuoran Fan $(\mathbb{D}$, Jilong $\mathrm{Xu}$, and Yuchen $\mathrm{Li}$ \\ College of Mathematical Sciences, Ocean University of China, Qingdao, Shandong, China \\ Correspondence should be addressed to Zhuoran Fan; fanzhuoran@stu.ouc.edu.cn
}

Received 23 April 2021; Accepted 10 June 2021; Published 23 June 2021

Academic Editor: Chun Lu

Copyright (C) 2021 Zhuoran Fan et al. This is an open access article distributed under the Creative Commons Attribution License, which permits unrestricted use, distribution, and reproduction in any medium, provided the original work is properly cited.

\begin{abstract}
In this paper, we select eight indicators from the aspects of an enterprise's bill transaction information, namely, whether the enterprise's loan is in breach of contract, effective invoice rate, total utilization rate of price and tax, negative invoice rate, strength of enterprise, coefficient of variation, flow efficiency of assets, and influence of upstream and downstream enterprises; then, we construct an evaluation index system. According to different industries, different categories, and the impact of random factors, we divide the types of enterprises into 10 categories. Then, we use three kinds of Poisson random numbers to carry out numerical simulation on the total price and tax of enterprises in different industries under the influence of COVID-19.
\end{abstract}

\section{Background}

When banks provide loans to small- and medium-sized and microenterprises (small- and medium-sized and microenterprises are abbreviated as SMMEs), they often judge whether to lend or not through credit risk assessment. Because of the lack of mortgage assets in SMMEs, the bank will make credit risk assessment based on the credit policy, influence, strength, and stability of supply and demand relationship of the enterprise, and then determine whether to lend, loan amount, interest rate and term, and other credit strategies. Some corporate banks have credit records, some have no credit records. However, in the face of the impact of sudden random factors on enterprises, how to give the credit strategy when the annual total credit is fixed.

\section{The Selection of Credit Risk Quantitative Index}

This paper analyzes the relevant data indicators of enterprises with credit records, takes into account the actual situation affecting the credit problems of SMMEs and refers to the advanced international standards, and selects eight quantitative indicators affecting the credit risk of enterprises according to China's national conditions and the bank's credit policy:

(1) Whether the enterprise loan is in breach of contract is an important indicator for the bank to examine whether the enterprise can bring the money. Default is 0 and nondefault is $1 . W_{i}$ means whether $i$ th enterprise is in breach of contract. $W_{i}=0$ means the enterprise defaults, while $W_{i}=1$ means that the enterprise has not breached the contract

(2) Effective invoice rate: it is equal to the ratio of the number of valid invoices to the total number of invoices. $B_{i}$ is used to denote the effective invoice rate of the $i$ th enterprise, $Y F_{i}$ indicates the number of valid invoices for the $i$ th enterprise, and $A_{i}$ represents the total invoice number of the $i$ th enterprise. Thus, the corresponding formula of the effective invoice rate of the $i$ th enterprise is as follows:

$$
B_{i}=\frac{Y F_{i}}{A_{i}}
$$

(3) Utilization rate of total price and tax: it is equal to the ratio of the total price and tax of the valid invoice to 
the total price and tax of all invoices. Putting $\beta_{i}$ represents the utilization rate of the total price and tax of an effective invoice of the $i$ th enterprise

(4) Negative rate of invoice $z_{i}$ : it is equal to the ratio of the number of invoices of the $i$ th enterprise whose value of the total invoice price and tax is "-" to the number of total invoices of the $i$ th enterprise

(5) $\mathrm{EVA}_{i}$ : it is equal to the ratio of the difference between the total price and tax of the output and input of the $i$ th enterprise to the total price and tax of input, which indicates the strength of the enterprise. Putting $S_{i}$ represents the total price and tax of the output (sales revenue) of the $i$ th enterprise, and $J_{i}$ represents the total price and tax of the $i$ th enterprise's input (purchased products), which uses the following corresponding formula:

$$
\mathrm{EVA}_{i}=\frac{S_{i}-J_{i}}{J_{i}}
$$

(6) Coefficient of variation: it indicates the stability of supply and demand relationship of enterprises. Using $c_{i}$ represents the coefficient of variation of the $i$ th enterprise. $x_{i j}$ represents the total input price and tax of the $i$ th enterprise in the $j$ th month, $s_{i j}$ is the total output value tax of the $i$ th enterprise in the $j$ th month, and $I_{i j}$ represents the net income of the $i$ th enterprise in the $j$ th month. If $x_{i j}=0$, let us take directly $\mathrm{EVA}_{i j}=0$. The corresponding formula is follows:

$$
\begin{aligned}
I_{i j} & =S_{i j}-x_{i j}, \\
\mathrm{EVA}_{i j} & =\frac{I_{i j}}{x_{i j}}, \\
c_{i} & =\frac{\sqrt{(1 / n) \sum_{j=1}^{12}\left(\mathrm{EVA}_{i j}-\overline{\mathrm{EVA}_{i j}}\right)^{2}}}{(1 / n) \sum_{j=1}^{12} \mathrm{EVA}_{i j}},
\end{aligned}
$$

where $\overline{\mathrm{EVA}_{i j}}$ represents the average value of $\mathrm{EVA}_{i j}$ in 12 months of the $i$ th enterprise

(7) Liquidity efficiency of assets: it refers to the comparative relationship between current assets and current liabilities of SMMEs in the same period, that is, the short-term solvency of SMMEs

The following table shows the asset flow data of the $i$ th enterprise in 12 months, as shown in Table 1.

The net income of the previous month is transferred to the next month as part of the next month's input, which shows the liquidity of funds. The liquidity efficiency of the $i$ th enterprise asset $\mu_{i}$ can be expressed as follows:

$$
\mu_{i}=\frac{m}{12}
$$

where 12 represents 12 months, and $m$ refers to the number greater than 0 in $\mathrm{EVA}_{i j}$ of $i$ th enterprise in 12 months. In fact, $\mu_{i}$ is the proportion of the number of months whose value is greater than 0 to the total number of months. The larger the value indicates that the better the flow efficiency of $i$ th enterprise.

(8) Influence of upstream and downstream enterprises $v_{i}$ : the influence is expressed by the maximum number of effective cooperation between the $i$ th enterprise and upstream and downstream enterprises. In order to quantitatively describe the influence of upstream and downstream enterprises, the influence function of upstream and downstream enterprises is introduced with reference to the negative exponential function of the psychological curve [1]:

$$
v_{i}=1-e^{-\left(n_{i}\right)^{1 / 3}},
$$

where $n_{i}$ refers to the largest number of input invoice and output invoice of the $i$ th enterprise in 12 months. Following the increase of $n_{i}$, the influence of upstream and downstream enterprises $v_{i}$ will also increase.

In the quantitative index system affecting the credit risk of SMMEs, the first to fourth indexes reflect the reputation of enterprises, the fifth index reflects the strength of enterprises, the sixth index reflects the stability of the supply and demand relationship of enterprises, the seventh index reflects the size of the credit risk of enterprises, and the eighth index reflects the influence of enterprises and upstream and downstream enterprises.

\section{Comprehensive Evaluation of Credit Risk Quantitative Index System}

In order to eliminate dimension and the positive and negative effects of index, in this paper, the fuzzy membership method is used to standardize the index. Let $y_{t j}$ be the $t$ th index value of the $j$ th evaluation object; $w_{t j}$ be the standardized value of the $t$ th index of the $j$ th evaluation object and $n$ be the number of objects to be evaluated. Then, the positive index standardization formula (6) and the negative index standardization formula (7) can be used to standardize the index [2]:

$$
\begin{aligned}
w_{t j}= & \frac{y_{t j}-\min _{1 \leq j \leq n} y_{t j}}{\max _{1 \leq j \leq n} y_{t j}-\min _{1 \leq j \leq n} y_{t j}}, \\
w_{t j}= & \frac{\max _{1 \leq j \leq n} y_{t j}-y_{t j}}{\max _{1 \leq j \leq n} y_{t j}-\min _{1 \leq j \leq n} y_{t j}} .
\end{aligned}
$$

Among the 8 indicators of the quantitative index system affecting credit risk of SMMEs, the fourth indicator (negative invoice rate) and the sixth indicator (enterprise coefficient of variation) are both negative indicators, which need to be 
TABle 1: Asset flow data of enterprises.

\begin{tabular}{lcclc}
\hline Month & 1 & 2 & $\cdots$ & 12 \\
\hline Total of input price and tax & $x_{i 1}$ & $x_{i 2}$ & $\cdots$ & $x_{i, 12}$ \\
Total of output price and tax & $s_{i 1}$ & $s_{i 2}$ & $\cdots$ & $s_{i, 12}$ \\
Net income & $I_{i 1}=s_{i 1}-x_{i 1}$ & $I_{i 2}=I_{i 1}+s_{i 2}-x_{i 2}$ & $\cdots$ & $I_{i, 12}=I_{i, 11}+s_{i, 12}-x_{i, 12}$ \\
EVA $_{i j}$ & $I_{i 1} / x_{i 1}$ & $I_{i 2} / x_{i 2}$ & $\cdots$ & $I_{i 12} / x_{i 12}$ \\
\hline
\end{tabular}

processed with the help of formula (7), while other indicators are calculated with the help of formula (6).

The following uses the entropy weight TOPSIS method to evaluate the credit risk quantitative index system of SMMEs. On the one hand, the entropy weight method is used to determine the coefficient of the credit risk quantitative index system. On the other hand, the TOPSIS method, that is, the technology of approaching the ideal solution, is used to determine the ranking of the evaluated object $n$ SMMEs. The core idea of the TOPSIS method is to define the positive ideal solution and negative ideal solution of the decision problem, and then compare and evaluate the distance between the solution and the positive ideal solution and negative ideal solution, and finally calculate the relative closeness degree between each solution and the ideal solution, and order the advantages and disadvantages of the solution.

3.1. Entropy Weight Method Being Used to Calculate the Objective Weight of Indexes. Set $w_{i j}$ as the normalized value of the $j$ th indicator in the $i$ th system, where $i=1,2, \cdots, n$ and $j=1,2, \cdots, 8$. For a given index $j$, the larger the difference of $w_{i j}$, the larger the comparative effect of this index has on the system, that means the more information the index contains and transmits.

The specific steps of the entropy method to determine the index weight are as follows:

(i) Calculating the entropy value of 8 indicators such as effective invoice rate. Set $e_{j}$ as the entropy value of thejth index, the solution process is as follows [3]:

$$
\begin{aligned}
p_{i j} & =\frac{w_{i j}}{\sum_{i=1}^{n} w_{i j}}, \\
e_{j} & =-\frac{1}{\ln n} \sum_{i=1}^{n} p_{i j} \ln p_{i j},
\end{aligned}
$$

where $p_{i j}$ is the characteristic proportion of the $j$ th index in the $i$ th system, $i=1,2, \cdots, n$ and $j=1,2, \cdots, 8 . \sum_{i=1}^{n} w_{i j}$ are the sum of all system observation data of the $j$ th indicator

(ii) Calculation of the coefficient of variance $g_{j}$ of the $j$ th index $g_{j}=1-e_{j}$

(iii) Determine the weight coefficients of 8 indexes $s_{j}=\left(g_{j} / \sum_{j=1}^{8} g_{j}\right)$
3.2. Weighting of Standardized Data. Let $y_{i j}$ be the weighted value of the $j$ th index standardized data of the $i$ th SMMEs, $w_{i j}$ be the normalized value of the $j$ th index observed value of the ith SMMEs, and $s_{j}$ be the weight coefficient. According to the weighting method, it can be seen that

$$
y_{i j}=w_{i j} s_{j}
$$

3.3. Determining the Positive and Negative Ideals of the Evaluation System. Set $y_{j}^{+}$and $y_{j}^{-}$as the maximum and minimum value of the $j$ th index observation data, respectively, $j=1,2, \cdots, 8$ :

$$
\begin{aligned}
& y_{j}^{+}=\max _{1 \leq k \leq n} y_{k j}, \\
& y_{j}^{-}=\min _{1 \leq k \leq n} y_{k j} .
\end{aligned}
$$

It is easy to know that the positive and negative ideal solutions of the evaluation system are, respectively, $y_{j}^{+}=\left(y_{1}^{+}\right.$, $\left.y_{2}^{+}, \cdots, y_{8}^{+}\right)$and $y_{j}^{-}=\left(y_{1}^{-}, y_{2}^{-}, \cdots, y_{8}^{-}\right)$.

3.4. Calculating the Euclidean Distance between the Evaluation System and the Ideal Solution. Let $d_{i}^{+}$be the Euclidean distance between the weighted value of the $i$ th enterprise and the positive ideal solution and $d_{i}^{-}$be the Euclidean distance between the weighted value of the $i$ th enterprise and the negative ideal solution. Then

$$
\begin{aligned}
& d_{i}^{+}=\sqrt{\left(y_{1}^{+}-y_{i 1}\right)^{2}+\left(y_{2}^{+}-y_{i 2}\right)^{2}+\cdots+\left(y_{8}^{+}-y_{i 8}\right)^{2}} \\
& d_{i}^{-}=\sqrt{\left(y_{1}^{-}-y_{i 1}\right)^{2}+\left(y_{2}^{-}-y_{i 2}\right)^{2}+\cdots+\left(y_{8}^{-}-y_{i 8}\right)^{2}} .
\end{aligned}
$$

3.5. Calculating the Relative Closeness Evaluation Result. Set $f_{i}$ as the relative closeness of all the indexes and the ideal solution of the $i$ th enterprise, then

$$
f_{i}=\frac{d_{i}^{-}}{d_{i}^{-}+d_{i}^{+}}
$$

where $i=1,2, \cdots, n$.

Determine the development status of the evaluated index by calculating the closeness. The greater the relative closeness $f_{i}$, the closer the evaluated index is to the ideal solution, and the better the development status. 


\section{Banks' Credit Strategies for SMMEs under Random Factors}

Let $x_{i}$ be the amount of the bank's loan to the ith SMMEs and $l_{\mathrm{i}}$ be the interest rate of the bank's loan to the ith SMMEs. Whether the bank gives loans to ith SMMEs, we use the 0-1 function

$$
c_{i}=\left\{\begin{array}{l}
1, \text { bank made a loan to the } i \text { th enterprise } \\
0, \text { bank does not lend to the } i \text { th enterprise }
\end{array}\right.
$$

The production, operation, and economic benefits of enterprises may be affected by some unexpected factors, and the size of the impact is related to different industries and different types of enterprises. For example, when COVID-19 became widespread, the demand for medical services and products produced by healthcare companies increased rapidly. With the help of relevant state policies, the total credit amount of banks to such healthcare companies and health enterprises will increase. At the same time, in order to avoid the rapid transmission of COVID-19, the state often needs to cut off some transmission routes. For example, during the outbreak of COVID-19, the state issued policies to close some self-employed small- and mediumsized enterprises, so as to reduce the movement of people and avoid cross-infection caused by too many people. In this regard, banks will reduce the total amount of credit to such self-employed SMMEs to avoid credit risk.

According to different industries, different categories, and the size of the impact, we classify enterprises as follows: self-employed enterprises, trade and transportation industry, literature and art advertising industry, manufacturing industry, service industry, financial investment industry, medical and health industry, high-tech enterprises, catering industry, and other industries.

In order to visually show the impact of credit risk and possible sudden factors on each enterprise, we carry out the numerical fluctuation of the total input price tax and the total output price tax of 10 types of enterprises. According to the actual impact of COVID-19 on society, the total input price and tax and the total output price and tax of the medical and health industry should be increased, while the total input price and tax and the total output price and tax of the individual business should be reduced. The concrete method is to add random numbers (Poisson random numbers) that are divided into three types for simulation.

The first category is to increase the total input and output tax of the medical and health industry, and the total input and output tax are, respectively, $J_{i}$ and $S_{i}$. By adding random number $\alpha_{i}(0 \sim 100 \%)$, the total input price and tax and the total sales tax after the influence are, respectively $\left(1+\alpha_{i}\right) J_{i}$ and $\left(1+\alpha_{i}\right) S_{i}$. In MATLAB software, the function alphal $=$ rand (length(location_a), 1 ) is used to achieve this $[4,5]$.

In the second category, for self-employed enterprises, the total input price and tax and the total output price and tax of the catering industry are reduced. The original total input price and tax and the total output price and tax are, respectively, $J_{i}$ and $S_{i}$. By adding random number $\gamma_{i}(-100 \% \sim 0)$, the total input price and tax and the total output price and tax are $\left(1+\gamma_{i}\right) J_{i}$ and $\left(1+\gamma_{i}\right) S_{i}$. This is achieved with the help of the functiongammal $=$ rand (length (location_g), 1 ).

In the third category, the influence of other industries is relatively small, and the random number $\varphi_{i}(-50 \% \sim 50 \%)$ is added and fluctuates randomly, and the original total of the input price and tax and the total of the output price and tax are $J_{i}$ and $S_{i}$, respectively. The total input price and tax and output price and tax are $\left(1+\varphi_{i}\right) J_{i}$ and $\left(1+\varphi_{i}\right) S_{i}$. This is achieved with the help of the function phil $=$ rand (length(location_p), 1$) / 2$.

\section{Multiobjective Planning Strategy of SMME's Credit under Random Factors}

When the COVID-19 outbreak occurred, the demand for services and products provided by medical and health enterprises also increased rapidly, and the resulting enterprise profits also increased, so the ability of enterprises to repay loans increased. It is a pity that the profit of the selfemployed enterprise is reduced or stagnated, and the ability to repay the loan is weakened. Due to the impact of unexpected factors, the repayment ability is weakened and the bank's income is affected.

5.1. Determination of Objective Function. From the front, we can see that $f_{i}$ means the comprehensive evaluation score of the $i$ th enterprise out of $n$ enterprises. Let

$$
\begin{array}{ll}
f_{\text {min }}=\min \left\{f_{i}\right\}, & i=1,2, \cdots n, \\
f_{\text {max }}=\max \left\{f_{i}\right\}, & i=1,2, \cdots n .
\end{array}
$$

Let the $i$ th enterprise repayment for the bank loan ratio be $\tau_{i}$. Taking it here

$$
\tau_{i}=\frac{f_{i}-f_{\min }}{f_{\max }-f_{\min }} .
$$

Thus, the amount of the loan that the $i$ th enterprise can repay is $\tau_{i} x_{i}$. To establish the objective function

$$
\max \sum_{i=1}^{n} c_{i}\left(1-f_{i}\right) l_{i} \tau_{i} x_{i}
$$

On the other hand, the smaller the bank's lending risk, the better. $f_{i} / J_{i}$ indicates the unit capital risk of the $i$ th SMMEs, and $x_{i}\left(f_{i} / J_{i}\right)$ represents the investment risk brought by the capital flow $x_{i}$ of the $i$ th SMMEs, and establishes an objective function for this purpose:

$$
\min \sum_{i=1}^{n} c_{i} x_{i} \frac{f_{i}}{J_{i}}
$$

On the other hand, the bank loan amount should take into account the business strength of the enterprise. This paper uses the sample variance index of loan amount and total input price and tax to describe the balance of credit amount, and establishes the objective function for this purpose: 


$$
\min s^{2}=\frac{1}{n-1} \sum_{i=1}^{n}\left(\frac{x_{i}}{J_{i}}-\frac{1}{n} \sum_{i=1}^{n} \frac{x_{i}}{J_{i}}\right)^{2} .
$$

\subsection{Determination of Constraints}

(i) The loan limit of the established bank to the enterprise determined to be loaned is 10-100 (ten thousand), so

$$
10 \leq x_{\mathrm{i}} \leq 100, \quad i=1,2, \cdots, n
$$

(ii) The annual loan interest rate of the bank to the enterprise determined to lend is $4 \% \sim 15 \%$. Thus

$$
4 \% \leq l_{\mathrm{i}} \leq 15 \%, \quad i=1,2, \cdots, n .
$$

(iii) The balance of a bank's investment in enterprises. It's represented by $x_{i} / J_{i}$. The demand for services and products provided by medical and health enterprises is increasing rapidly. Therefore, the total input price and tax of such enterprises should also be increased, and the amount of bank loans to such enterprises should be increased. When the number of self-employed enterprises decreases or stagnates, the total input value and tax should also be reduced, and the amount of bank loans to such enterprises should be reduced. The upper and lower limits of the total balance of input price and tax for medical and health input are adjusted to 0.8 and 2 . Considering that an individual business cannot be given a loan completely, the upper and lower limits of the total balance of input price and tax of an individual business are adjusted to 0.3 and 1, the upper and lower limits of other industries remain at 0.5 and 1.5. Set $M=$ "medical enterprise code"; $G=$ "individual enterprise code"; and $Q=$ "all other enterprise codes". We agreed that

$$
\begin{gathered}
0.8 \leq \frac{x_{i}}{J_{i}} \leq 2, \quad i \in M, \\
0.3 \leq \frac{x_{i}}{J_{i}} \leq 1, \quad i \in G, \\
0.5 \leq \frac{x_{i}}{J_{i}} \leq 1.5, \quad i \in Q .
\end{gathered}
$$

(iv) Whether the bank loans to the enterprise and the loan amount is consistent, let $\delta$ be a very small positive number and $M$ be a very large positive number. The values of 1 and 0 of $c_{i}$, respectively, indicate that the bank loans to the $i$ th enterprise and does not lend to the $i$ th enterprise. In order to ensure the consistency of bank loans to the enterprise and the loan amount, there are constraints

$$
\delta c_{i} \leq x_{i} \leq M c_{i}
$$

(v) Total amount of loan. Assuming that the total amount of loan is 100 million when the bank loans to $n$ enterprises, the unit here takes 10000 yuan. We have

$$
\sum_{i=1}^{n} x_{i}=10^{4}
$$

\section{Example Checking}

This paper verifies the multiobjective planning strategy of SMMEs under the influence of COVID-19 by using the related data. The original data of this paper comes from the data of competition question C for CUMCM-2020 (China University mathematical modeling competition), which can be downloaded publicly [6] (http://www.mcm.edu.cn/html_ cn/node/10405905647c52abfd6377c0311632b5.html).

Firstly, the Poisson random number is considered, and with the help of the TOPSIS evaluation method, the scores and ranking comparison table of 302 enterprises before and after the introduction of random distribution are obtained [7-17]. The scores and ranking of the top 20 enterprises with enterprise number before and after the introduction of random distribution are shown in Table 2.

It can be seen from Table 2 that, after the introduction of random distribution, the ranking of enterprises with enterprise labels ranging from 1 to 20 changed correspondingly-some changed greatly, while some changed less-indicating that our model has good practicability.

After the introduction of random distribution, the changes in scores and rankings.

of the top 20 enterprises among the 302 enterprises are shown in Table 3.

As can be seen from Table 3, after the introduction of random distribution, the number of the top 20 enterprises is basically still in the top 20, indicating that our comprehensive evaluation method is relatively good and the ranking distribution is relatively stable.

From Table 4, we can see the ranking changes of enterprises in the case of occurrence of emergent factors and absence of emergent factors. It can be found that under the influence of COVID-19, the rating and ranking of enterprises in the medical and health industry have increased, indicating that under the influence of COVID-19, such enterprises have a good credit situation and a low credit risk. However, the decline in the score and ranking of self-employed enterprises indicates that under the influence of COVID-19, the credit situation of such enterprises is poor and the credit risk is high, which is in line with the actual situation. It indicates that our TOPSIS evaluation method is effective and can be better applied to the situation when random factors occur.

When the total annual credit of the bank is 100 million yuan, we use the data given in the attached table of question $\mathrm{C}$ to establish the multiobjective programming model of 302 enterprises. 
TABLE 2: Comparison of scores and rankings of the top 20 enterprises with enterprise numbers before and after the introduction of random distribution.

\begin{tabular}{|c|c|c|c|c|c|}
\hline \multicolumn{3}{|c|}{$\begin{array}{l}\text { The score results of entropy weight method before introducing a } \\
\text { random distribution }\end{array}$} & \multicolumn{3}{|c|}{$\begin{array}{c}\text { The score results of entropy weight method after introducing a } \\
\text { random distribution }\end{array}$} \\
\hline Enterprise numbers & Score $f_{i}$ & Ranking & Enterprise numbers & Score $f_{i}$ & Ranking \\
\hline 1 & 0.03470546 & 133 & 1 & 0.01051545 & 258 \\
\hline 2 & 0.03473871 & 132 & 2 & 0.01009714 & 271 \\
\hline 3 & 0.26589653 & 77 & 3 & 0.2664342 & 52 \\
\hline 4 & 0.29959602 & 8 & 4 & 0.36079418 & 3 \\
\hline 5 & 0.26882309 & 21 & 5 & 0.31805003 & 22 \\
\hline 6 & 0.2663194 & 61 & 6 & 0.04038756 & 92 \\
\hline 7 & 0.26669382 & 46 & 7 & 0.01158391 & 189 \\
\hline 8 & 0.26632932 & 59 & 8 & 0.0171994 & 112 \\
\hline 9 & 0.26681615 & 40 & 9 & 0.01643889 & 114 \\
\hline 10 & 0.26611135 & 72 & 10 & 0.11524284 & 72 \\
\hline 11 & 0.26909606 & 19 & 11 & 0.32030139 & 17 \\
\hline 12 & 0.2667195 & 44 & 12 & 0.31590827 & 32 \\
\hline 13 & 0.26702299 & 31 & 13 & 0.01160196 & 187 \\
\hline 14 & 0.26627581 & 63 & 14 & 0.11280042 & 75 \\
\hline 15 & 0.26699131 & 33 & 15 & 0.31609219 & 31 \\
\hline 16 & 0.27680573 & 15 & 16 & 0.32686684 & 12 \\
\hline 17 & 0.2469376 & 90 & 17 & 0.29235498 & 47 \\
\hline 18 & 0.26674657 & 42 & 18 & 0.31711769 & 26 \\
\hline 19 & 0.26660041 & 50 & 19 & 0.31528929 & 40 \\
\hline 20 & 0.24583911 & 93 & 20 & 0.24091041 & 58 \\
\hline
\end{tabular}

TABLE 3: Changes in scores and rankings of the top 20 companies after the introduction of random distribution.

\begin{tabular}{|c|c|c|c|c|c|}
\hline \multicolumn{3}{|c|}{$\begin{array}{l}\text { The score results of entropy weight method before introducing a } \\
\text { random distribution }\end{array}$} & \multicolumn{3}{|c|}{$\begin{array}{c}\text { The score results of entropy weight method after introducing a } \\
\text { random distribution }\end{array}$} \\
\hline Enterprise numbers & Score $f_{i}$ & Ranking & Enterprise numbers & Score $f_{i}$ & Ranking \\
\hline 206 & 0.65353762 & 1 & 206 & 0.74570025 & 1 \\
\hline 30 & 0.51530701 & 2 & 30 & 0.55732306 & 2 \\
\hline 4 & 0.36079418 & 3 & 237 & 0.33358854 & 3 \\
\hline 107 & 0.34892084 & 4 & 235 & 0.31445308 & 4 \\
\hline 92 & 0.34436155 & 5 & 89 & 0.31144136 & 5 \\
\hline 89 & 0.34363768 & 6 & 107 & 0.30352414 & 6 \\
\hline 76 & 0.34281575 & 7 & 220 & 0.30110706 & 7 \\
\hline 220 & 0.34233996 & 8 & 4 & 0.29959602 & 8 \\
\hline 122 & 0.33108545 & 9 & 92 & 0.2928879 & 9 \\
\hline 26 & 0.32893502 & 10 & 76 & 0.29120591 & 10 \\
\hline 62 & 0.32855488 & 11 & 122 & 0.28217424 & 11 \\
\hline 16 & 0.32686684 & 12 & 26 & 0.28128101 & 12 \\
\hline 38 & 0.32600357 & 13 & 38 & 0.28008684 & 13 \\
\hline 45 & 0.32299682 & 14 & 62 & 0.27817557 & 14 \\
\hline 110 & 0.32166147 & 15 & 16 & 0.27680573 & 15 \\
\hline 33 & 0.32044747 & 16 & 45 & 0.27234886 & 16 \\
\hline 11 & 0.32030139 & 17 & 33 & 0.27128483 & 17 \\
\hline 53 & 0.3194912 & 18 & 110 & 0.27112156 & 18 \\
\hline 111 & 0.31946501 & 19 & 11 & 0.26909606 & 19 \\
\hline 63 & 0.31856213 & 20 & 63 & 0.26895159 & 20 \\
\hline
\end{tabular}


TABLE 4: Changes in medical and individual business scores and rankings after the introduction of random distribution.

\begin{tabular}{|c|c|c|c|c|c|}
\hline \multicolumn{3}{|c|}{$\begin{array}{c}\text { The score results of entropy weight method before introducing } \\
\text { a random distribution }\end{array}$} & \multicolumn{3}{|c|}{$\begin{array}{c}\text { The score results of entropy weight method after introducing a } \\
\text { random distribution }\end{array}$} \\
\hline Enterprise numbers & Score $f_{i}$ & Ranking & Enterprise numbers & Score $f_{i}$ & Ranking \\
\hline E195 (medical) & 0.266610 & 48 & E195 (medical) & 0.314380 & 44 \\
\hline E398 (medical) & 0.014558 & 189 & E398 (medical) & 0.012037 & 166 \\
\hline E420 (medical) & 0.014021 & 227 & E420 (medical) & 0.013773 & 184 \\
\hline E373 (individual) & 0.014911 & 162 & E373 (individual) & 0.009712 & 279 \\
\hline E124 (individual) & 0.034705 & 133 & E124 (individual) & 0.010516 & 258 \\
\hline E125 (individual) & 0.034739 & 132 & E125 (individual) & 0.010516 & 271 \\
\hline
\end{tabular}

TABLE 5: Analysis of different results obtained by different scale coefficients of the three objective functions.

\begin{tabular}{lccccccccccc}
\hline Plan & 1 & 2 & 3 & 4 & 5 & 6 & 7 & 8 \\
\hline$u(1)$ & 0.7 & 0.6 & 0.6 & 0.5 & 0.6 & 0.5 & 0.4 & 0.3 \\
$u(2)$ & 0.2 & 0.2 & 0.1 & 0.25 & 0.15 & 0.15 & 0.15 & 0.15 \\
$u(3)$ & 0.1 & 0.2 & 0.3 & 0.25 & 0.25 & 0.35 & 0.45 & 0.55 \\
The number of different values of the loan amount & 7 & 9 & 9 & 8 & 11 & 17 & 19 & 20 \\
\hline
\end{tabular}

The multiobjective function includes the following: $\max$ $\sum_{i=1}^{302} c_{i}\left(1-f_{i}\right) l_{i} \tau_{i} x_{i}, \min \sum_{i=1}^{302} c_{i} x_{i}\left(f_{i} / J_{i}\right)$, and

$$
\min s^{2}=\frac{1}{301} \sum_{i=1}^{302}\left(\tau_{i} \frac{x_{i}}{J_{i}}-\frac{1}{302} \sum_{i=1}^{302} \tau_{i} \frac{x_{i}}{J_{i}}\right)^{2} .
$$

The constraint conditions are as follows:

$$
\left\{\begin{array}{l}
10 \leq x_{\mathrm{i}} \leq 100, \\
4 \% \leq l_{\mathrm{i}} \leq 15 \%, \\
\tau_{i}=\frac{f_{i}-f_{\min }}{f_{\max }-f_{\min }}, \\
0.8 \leq \frac{x_{i}}{J_{i}} \leq 2, \quad i \in M \\
\delta c_{i} \leq x_{i} \leq M c_{i}, \\
\sum_{k=1}^{302} x_{i}=10^{4} .
\end{array}\right.
$$

The software programming of Lingo is used to solve the above multiobjective function programming model [18]. In the three target functions, let $u(j),(j=1,2,3)$ be the scale coefficient of the $j$ th objective function, which satisfies

$$
u(1)+u(2)+u(3)=1
$$

Set three different proportional coefficients and get different results of different loan amounts, which are analyzed in the following list (see Table 5).

According to the analysis in Table 5, the balance of credit amount is important for banks. Finally, the eighth plan is selected to obtain the specific credit plan for 302 SMMEs, as shown in Table 6 below. The loan amount of enterprises not listed in Table 6 is 100,000 yuan.

It can be found that during the COVID-19 epidemic, due to the rapid increase in the demand for the services and products provided by the medical and health enterprises, the investment of the finally obtained bank in this industry also increased, the sales of the self-employed industry decreased or stagnated, and the investment of the finally obtained bank in this industry also decreased or stagnated. The investment of banks in other industries is also adjusted accordingly to maintain the survival and operation of the industry, which is more consistent with the actual situation and demonstrates the effectiveness and practicability of our model.

\section{Sensitivity Analysis of the Model}

The sensitivity of the model is used to analyze the sensitivity and stability of the model. In order to test the stability and effectiveness of the multiobjective programming strategy model, sensitivity analysis is carried out.

In the case of COVID-19, 3 random Poisson numbers were added to simulate the total value of the total tax and total sales tax in each industry. In order to fully demonstrate the sensitivity of the model, we changed the number of algorithm runs and record the average scores of the 302 comprehensive evaluation scores obtained by each algorithm; then, the average score of the comprehensive evaluation of the 20 algorithms was obtained and drawn. The results are shown in Figure 1.

By checking whether the average value of the comprehensive evaluation score is stable and centralized when the algorithm runs for 20 times, we can verify whether the model is stable. One can find that the average value of the comprehensive evaluation score of 20 times is relatively centralized and stable, floating in a certain range. It can be seen that our model is stable and practical. 
TABLE 6: List of the specific amount of 100 million yuan loan from the bank to 302 SMMEs (yuan).

\begin{tabular}{|c|c|}
\hline Enterprise number & Loan amount \\
\hline 133 & 880344.8 \\
\hline 147 & 548104 \\
\hline 149 & 864340.1 \\
\hline 166 & 532681.5 \\
\hline 167 & 867680.4 \\
\hline 171 & 150709.4 \\
\hline 173 & 726597.9 \\
\hline 178 & 836082.4 \\
\hline 179 & 646818.7 \\
\hline 182 & 425921 \\
\hline 187 & 402967.4 \\
\hline 190 & 414155.8 \\
\hline 191 & 735308.3 \\
\hline 193 & 338920 \\
\hline 198 & 732913.7 \\
\hline 205 & 313454.6 \\
\hline 211 & 798931.5 \\
\hline 242 & 184068.4 \\
\hline 1 & 1000000 \\
\hline 2 & 1000000 \\
\hline 212 & 1000000 \\
\hline 296 & 1000000 \\
\hline 39 & 1000000 \\
\hline 58 & 1000000 \\
\hline 100 & 1000000 \\
\hline 101 & 1000000 \\
\hline 103 & 1000000 \\
\hline 109 & 1000000 \\
\hline 124 & 1000000 \\
\hline 125 & 1000000 \\
\hline 126 & 1000000 \\
\hline 127 & 1000000 \\
\hline 128 & 1000000 \\
\hline 129 & 1000000 \\
\hline 130 & 1000000 \\
\hline 131 & 1000000 \\
\hline 132 & 1000000 \\
\hline 134 & 1000000 \\
\hline 135 & 1000000 \\
\hline 136 & 1000000 \\
\hline 137 & 1000000 \\
\hline 138 & 1000000 \\
\hline 229 & 1000000 \\
\hline 3 & 1000000 \\
\hline 139 & 1000000 \\
\hline 140 & 1000000 \\
\hline 141 & 1000000 \\
\hline 142 & 1000000 \\
\hline
\end{tabular}

TABle 6: Continued.

\begin{tabular}{|c|c|}
\hline Enterprise number & Loan amount \\
\hline 145 & 1000000 \\
\hline 148 & 1000000 \\
\hline 150 & 1000000 \\
\hline 153 & 1000000 \\
\hline 154 & 1000000 \\
\hline 155 & 1000000 \\
\hline 156 & 1000000 \\
\hline 157 & 1000000 \\
\hline 158 & 1000000 \\
\hline 159 & 1000000 \\
\hline 160 & 1000000 \\
\hline 161 & 1000000 \\
\hline 162 & 1000000 \\
\hline 163 & 1000000 \\
\hline 164 & 1000000 \\
\hline 165 & 1000000 \\
\hline 250 & 1000000 \\
\hline 4 & 100000 \\
\hline 169 & 1000000 \\
\hline 170 & 1000000 \\
\hline 174 & 1000000 \\
\hline 175 & 1000000 \\
\hline 176 & 1000000 \\
\hline 177 & 1000000 \\
\hline 181 & 1000000 \\
\hline 183 & 1000000 \\
\hline 184 & 1000000 \\
\hline 185 & 1000000 \\
\hline 186 & 1000000 \\
\hline 189 & 1000000 \\
\hline 196 & 1000000 \\
\hline 197 & 1000000 \\
\hline 199 & 1000000 \\
\hline 200 & 1000000 \\
\hline 201 & 1000000 \\
\hline 202 & 1000000 \\
\hline 203 & 1000000 \\
\hline 204 & 1000000 \\
\hline 258 & 1000000 \\
\hline 5 & 100000 \\
\hline
\end{tabular}

In this paper, the TOPSIS evaluation method is firstly used to get the score and ranking comparison of 302 enterprises before and after the introduction of a random number, and the ranking results are analyzed. Then, considering that different industries each have a different ability to repay loans when affected by COVID-19, the ratio factor that can repay bank loans is introduced, and considering the floating 


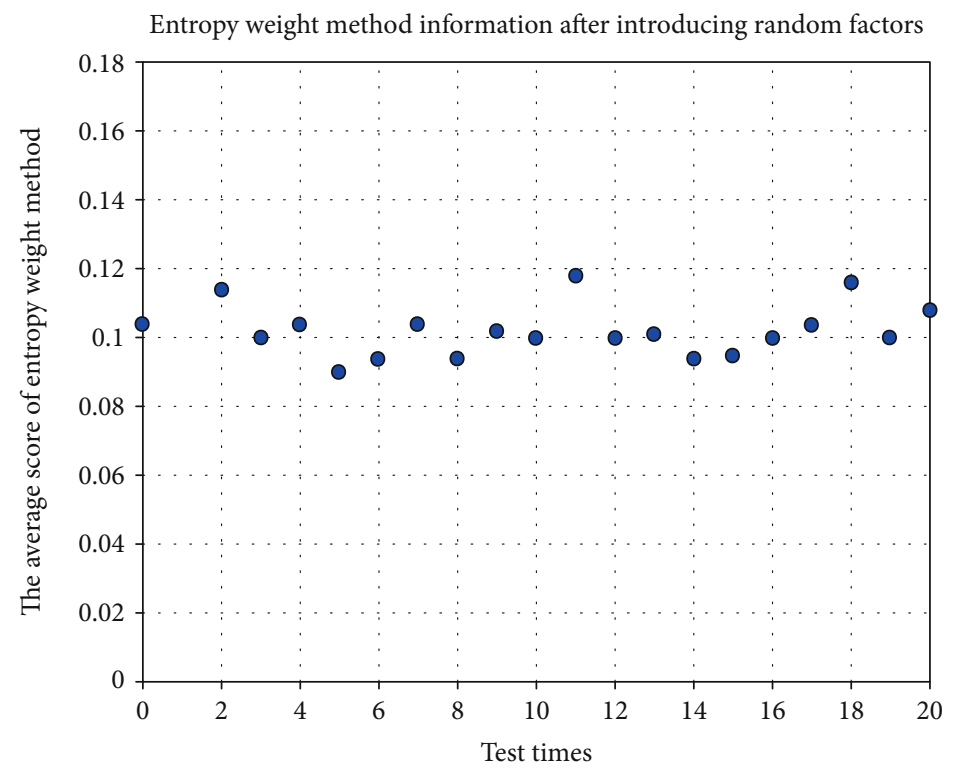

- Equal division of entropy weight method - Run number

FIGURE 1: Sensitivity inspection chart.

amount of loans in different industries under national conditions and policies, the objective function and constraints of the multiobjective credit optimization model are modified, and the multiobjective credit optimization model of enterprises influenced by COVID-19 is established. When the total amount is 100 million, the corresponding credit decision is made. Finally, sensitivity analysis is carried out to test the stability and effectiveness of the multiobjective programming strategy model.

\section{Data Availability}

The original data of this paper comes from the data of competition question C for CUMCM-2020 (China University mathematical modeling competition), which can be downloaded publicly. Download from the following website: http://www.mcm.edu.cn/html_cn/node/ 10405905647c52abfd6377c0311632b5.html. The later data used to support the findings of this study are included within the supplementary information file(s).

\section{Conflicts of Interest}

The authors declare that they have no conflicts of interest.

\section{Acknowledgments}

This work was supported by the Natural Science Foundation of Shandong Province of China (No. ZR2020QA078) and the National Natural Science Foundation of China (No. 12005110).

\section{Supplementary Materials}

We have uploaded three attachments. Annex 1.1: raw data on 302 enterprises without credit records which comes from the data of competition question C for CUMCM-2020. Annex 2: in this paper, we get the relevant data of 302 enterprises before and after the introduction of random distribution. Annex 3: Ligon Program Source Code. (Supplementary Materials)

\section{References}

[1] L. Zhang and X. Wang, "Analysis on dairy farmers' income based on Logit model," Economic Theory and Business Management, vol. 9, pp. 101-108, 2012.

[2] H. Yang and P. Fu, "Application of fuzzy comprehension evaluation based on entropy weight," Journal of North China Electric Power University, vol. 32, no. 5, pp. 104107, 2005.

[3] G. Li, G. Chi, and Y. Cheng, "Evaluation model and empirical study of human all-round development based on entropy weight and TOPSIS," Journal of Systems Engineering, vol. 26, no. 3, pp. 400-407, 2011.

[4] J. Zhuo, The Application of MATLAB in Mathematical Modeling, Beijing University of Aeronautics and Astronautics Press, Beijing, 2019.

[5] C. Gong and Z. Wang, Common Algorithm Assembly of MATLAB Language, Publishing House of Electronics Industry, Beijing, 2010.

[6] "The data of competition question C for CUMCM-2020 (China University mathematical modeling competition)," h t t p : / / w w w.mcm.edu.cn/html_cn/node/ 10405905647c52abfd6377c0311632b5.html.

[7] S. Si and X. Sun, Mathematical Modeling Algorithms and Applications, National Defense Industry Press, Beijing, 2011. 
[8] M. Liu and C. Bai, "Optimal harvesting of a stochastic mutualism model with regime-switching," Applied Mathematics and Computation, vol. 373, p. 125040, 2020.

[9] C. Lu, "Dynamics of a stochastic Markovian switching predator-prey model with infinite memory and general Lévy jumps," Mathematics and Computers in Simulation, vol. 181, pp. 316-332, 2021.

[10] B. Han, D. Jiang, B. Zhou, T. Hayat, and A. Alsaedi, "Stationary distribution and probability density function of a stochastic SIRSI epidemic model with saturation incidence rate and logistic growth," Chaos, Solitons \& Fractals, vol. 142, article 110519, 2021.

[11] C. Lu and X. Ding, "Periodic solutions and stationary distribution for a stochastic predator-prey system with impulsive perturbations," Applied Mathematics and Computation, vol. 350, pp. 313-322, 2019.

[12] C. Lu, G. Sun, and Y. Zhang, "Stationary distribution and extinction of a multi-stage HIV model with nonlinear stochastic perturbation," Journal of Applied Mathematics and Computing, 2021.

[13] M. Song, W. Zuo, D. Jiang, and T. Hayat, "Stationary distribution and ergodicity of a stochastic cholera model with multiple pathways of transmission," Journal of the Franklin Institute, vol. 357, no. 15, pp. 10773-10798, 2020.

[14] S. Zhang, T. Zhang, and S. Yuan, "Dynamics of a stochastic predator-prey model with habitat complexity and prey aggregation," Ecological Complexity, vol. 45, article 100889, 2021.

[15] M. Gao and D. Jiang, "Stationary distribution of a stochastic food chain chemostat model with general response functions," Applied Mathematics Letters, vol. 91, pp. 151-157, 2019.

[16] X. Zhang and Q. Yang, "Threshold behavior in a stochastic SVIR model with general incidence rates," Applied Mathematics Letters, vol. 121, article 107403, 2021.

[17] Q. Liu and D. Jiang, "Influence of the fear factor on the dynamics of a stochastic predator-prey model," Applied Mathematics Letters, vol. 112, article 106756, 2021.

[18] J. Xie and Y. Xue, Optimized Modeling with Lindo/Lingo Software, Tsinghua University Press, Beijing, 2005. 